\title{
Ma. Eugenia Chaoul Pereyra
}

Maestra en Historia Moderna y Contemporánea de México. Profesora asociado $\mathrm{C}$ en el Instituto de Investigaciones Dr. José María Luis Mora. Ha publicado "Las escuelas municipales, un espejo de la ciudad: la gestión educativa del Ayuntamiento de México, 1867-1896", Anuario de Estudios Urbanos, UAMAzcapotzalco, 1999.

\section{Resumen}

Este artículo analiza la relación entre la comunidad magisterial y el Ayuntamiento de México. Da cuenta de los vínculos que se establecieron entre los preceptores municipales para proteger sus intereses y cómo el Ayuntamiento cubrió las demandas de exclusividad de la docencia municipal para asegurar una red clientelar y ganar autonomía en su gestión.

Palabras clave:

Ayuntamiento, maestros, clientelismo, gremio, ciudad.

\begin{abstract}
This article analyzes the relation between the teaching community and the government of Mexico City. It describes the ways established among municipal preceptors to protect their interests. It also focuses on how the city government covered the demands of exclusivity of municipal teaching, assuring a net of clients and autonomy in their work.
\end{abstract}

\section{Key words:}

City government, teachers, cliency, guild, city.

Fecha de recepción:

febrero de 2001

Fecha de aceptación:

septiembre de 2001 


\title{
El Ayuntamiento de la ciudad de México y los maestros municipales, 1867-1896
}

\author{
Ma. Eugenia Chaoul Pereyra
}

A 1 triunfo de la república, la instrucción pública fue un asunto de interés especial para el gobierno federal, y la prueba está en que menos de seis meses después de la entrada del presidente Juárez a la capital, se aprobó la ley orgánica de 1867 que venía a reglamentar el artículo $3^{\circ}$ de la Constitución de 1857 . Con esta ley y el reglamento de 1869, la enseñanza de primeras letras sería gratuita para los pobres y se pretendía hacerla obligatoria desde los cinco años de edad. Para lograr ese cometido, el ejecutivo federal otorgó a las municipalidades del Distrito Federal y territorios de Nayarit y Tepic la obligación de extender la educación de manera progresiva y sostener con sus fondos escuelas primarias de acuerdo con el número de habitantes. ${ }^{1}$

Si bien, el ámbito de validez territorial de la norma era restringido, la nueva legislación le permitió al gobierno federal ampliar su espacio de acción en

1 Las municipalidades deberían sostener con sus fondos una escuela por cada 500 habitantes, "si excedieren de 2000 se creará una escuela de cada sexo por cada 2000 habitantes"; además, el Ayuntamiento de la ciudad de México iniciaría su gestión con 24 planteles: doce para niños y doce amigas para niñas. Véase Dublán, Colección, 1867, t. 9, núm. 6182 , p. $754 ; 1869$, t. 9 , núm. 6692, pp. 753-762. torno a la educación básica e iniciar, durante el porfiriato, una progresiva apropiación de funciones docentes. A partir de la normatividad de 1867, el ejecutivo federal pudo trazar los objetivos políticos de la educación liberal y definir la orientación que debía tener, la laicidad de la misma y el precepto de obligatoriedad; los municipios, en cambio, tendrían que abocarse a los problemas escolares y al conjunto de decisiones que sobre la práctica fueran surgiendo de acuerdo con su gestión: distribución de escuelas gratuitas, habilitación de casas para establecimientos escolares, educación de adultos, reposición de inventarios y relación con profesores.

Con ello se desprendieron dos lógicas diferentes frente a la educación; mientras el gobierno federal insertaba los objetivos políticos de la instrucción pública en el marco de un plan y buscaba inducir la uniformidad y homogeneidad, el aspecto operativo le correspondía a los Ayuntamientos. De ellos, el de la ciudad de México enfrentaría un doble problema: por un lado, la capital se consideraba el escaparate de todos los cambios propuestos en materia educativa, y por otro, resultaba complejo administrar los problemas escolares en un ambiente urbano con grandes requerimientos. La calidad y el carácter de la gestión educativa municipal de la ciu- 
dad estarían determinados por múltiples factores: las presiones políticas, las demográficas, el control de los recursos económicos y la organización social.

Este artículo busca explorar la relación que mantuvo el Ayuntamiento de la ciudad de México con los profesores municipales durante los 29 años que duró su gestión educativa, entre 1867 y 1896. Los vínculos que estableció y las expectativas que generó en un grupo que se distinguía por ejercer una práctica común: la de educar.

Para algunos historiadores como Luz Elena Galván, los maestros durante la república restaurada y el porfiriato

fueron personas que durante muchos años habían luchado solas por su superación, tanto académica como económica [...] El maestro estaba solo, no era parte de una asociación, ni siquiera de un grupo. Él sabía que tenía que quedar bien con el presidente, ya que de no hacerlo, podía perder su única fuente de trabajo sin importar su antigüedad en el magisterio. ${ }^{2}$

Alberto Arnaut, por su parte plantea:

la relación contractual directa entre maestros y padres de familia paulatinamente va siendo reemplazada [en la república restaurada y el porfiriato] por otra de tipo laboral de los maestros con las autoridades municipales, estatales y federales. Por otra parte, los maestros dejan de rendirle cuentas a sus clientes para rendírselas a sus superiores en las oficinas escolares y educativas de los distintos niveles de gobierno. ${ }^{3}$

2 Galván, Soledad, 1991, p. 224.

${ }^{3}$ Arnaut, Historia, 1996, p. 25.
Desde mi punto de vista, esta imagen de "desprotección" o de simple relación contractual podía ser matizada, por lo menos para los maestros de la ciudad de México, a la luz de la actuación municipal. En ese sentido, parto del hecho de que, de la noche a la mañana, la normatividad de 1867 convirtió al municipio de la capital en el promotor más importante de la educación gratuita y, por consiguiente, en el principal empleador de maestros. ${ }^{4} \mathrm{~A}$ partir de entonces, la corporación enfrentaría un problema de distribución y asignación de puestos de trabajo; los maestros en cambio, buscarían lograr conservar los beneficios asociados con el ejercicio de su profesión. Entre ambos actores se establecería una relación de reciprocidad marcada por diferentes intereses. Para el Ayuntamiento, la relación con los profesores le permitiría fortalecer su autoridad, ganar prestigio y margen de acción frente al gobierno federal; los docentes, por su parte, buscarían establecer mecanismos que les permitieran mantener una comunidad cerrada, regular el acceso de nuevos candidatos y contar con ciertos beneficios. ${ }^{5}$ Esta apreciación resulta más clara si atendemos a lo que fue

${ }^{4}$ Si bien la Compañía Lancasteriana tenía escuelas muy numerosas, para 1868 el Ayuntamiento de la ciudad de México atendía en sus escuelas a $30 \%$ de la población escolar, en tanto que la Compañía sólo a 18\%. Además, el propio Ayuntamiento otorgaba una subvención anual a la Compañía de 3999.96 pesos. Véase Chaoul, "Instrucción”, 1998, pp. 21 y 69 .

s Sobre el tipo ideal de comunidad de Max Weber: "La mayor parte de los tipos de comunidad guarda alguna relación con la economía [...] Pretendemos hablar de economía [como] un acervo es- 
el sentido de la acción para ambos actores en la ciudad desde sus inicios.

\section{LOS INICIOS}

En el siglo XVIII, la educación primaria en la capital de Nueva España estaba en manos del gremio de maestros de primeras letras, cuyo objetivo era proteger a sus miembros de la competencia y asegurar la calidad de la instrucción. La organización gremial estaba presidida por un maestro mayor, quien podía asignar el puesto de preceptor de primeras letras a cualquier aspirante que fuera previamente examinado por él. Si había una escuela disponible y de acuerdo con su desempeño, el maestro mayor le otorgaba el cargo de manera vitalicia. Los preceptores incorporados tenían que estar seguros de contar con una clientela suficiente que, mediante sus cuotas, les permitiera pagar su manutención y los costos de entrada al gremio. Como parte de la organización, los maestros tenían que contribuir para el sostenimiento de la misma y dar una provisión para el socorro mutuo de sus miembros. ${ }^{6}$

Con las ideas ilustradas, la instrucción se concibió como un bien público en el sentido de que debía ser general para toda la población y se presentaba, además, como un elemento de utilidad públi$c a$, pues era instrumento de renovación para la prosperidad nacional. La idea de hacer extensiva la instrucción a toda la población estaba relacionada directa-

caso de medios, siendo esta situación causa de un comportamiento específico que lo tiene en cuenta". Véase Weber, Economía, 1977, t. 1, p. 273.

6 Tanck, Educación, 1977, pp. 87-142. mente con la limitación del gremio que monopolizaba la enseñanza básica y el deseo de que la educación fuera gratuita. Para llevar a cabo sus objetivos, el proyecto ilustrado dotó de nuevas funciones al Estado, mismas que quedarían finalmente plasmadas en la Constitución de Cádiz. La ley gaditana suspendió el monopolio de la enseñanza ejercido por el gremio de maestros y dotó a los Ayuntamientos con la función de supervisión y distribución de la educación como un bien público. ${ }^{7}$

La legislación gaditana sirvió de base a la del México independiente, y los municipios asumieron el papel de abrir escuelas, así como de examinar y vigilar a los maestros, tanto de las escuelas particulares como de las que estaban a su cargo. La docencia fue comparada con el libre ejercicio de todas las profesiones, concepto que reafirmaba el deseo de separar a la educación de las restricciones gremiales que habían estado vigentes durante el antiguo régimen.

Entre 1822 y 1833, el Ayuntamiento de la ciudad de México asumió la tarea de inspeccionar establecimientos particulares y municipales, de examinar profesores y de expedir licencias para establecer escuelas. Cada plantel educativo particular, autorizado por el municipio, debía contar con lugares "de gracia" o becas en sus establecimientos para niños que no podían pagar la cuota establecida por el profesor. ${ }^{8}$

Al tiempo que el Ayuntamiento de la ciudad asumía su papel como autori-

${ }^{7}$ Las ideas generales que se presentan son resultado de la lectura de los escritos: Tanck, "Cortes", 1979, pp. 3-34; “Tensión”, 1981, pp. 23-114.

8 'Tanck, "Ilustración", 1984, pp. 463-508. 
dad educativa, los preceptores de primeras letras intentaron formar una organización de maestros. El primer paso fue crear una Academia de Primera Enseñanza en 1827 , dedicada a perfeccionar la instrucción. No obstante, como apunta Tanck, la Academia que proponían

era diferente al gremio, porque entre sus fundadores y miembros contaba con hombres del Estado que no eran maestros. También sus estatutos iban dirigidos sólo al mejoramiento de la calidad de la enseñanza por medio de la preparación de textos y entrenamiento de nuevos preceptores. No se redactaron artículos sobre la limitación del ejercicio de la profesión y sus miembros, ni sobre protección o ayuda mutua de los maestros. 9

Un nuevo intento se llevó a cabo en 1835 con el Colegio Académico Mejicano de Educación Primaria, que a diferencia de la organización de 1827 , incluía la idea de una cuota mensual para socorrer a sus miembros y buscaba ejercer la certificación de aspirantes a la profesión y vigilancia del ejercicio del magisterio. ${ }^{10}$ Parecería con ello que el tipo de organización gremial había reaparecido, aunque no con la función de examinar a los aspirantes al magisterio y restringir el acceso a la docencia, funciones que permanecieron como prerrogativas exclusivas del Ayuntamiento. Al fin y al cabo, la profesión docente era una profesión libre.

Si bien es cierto que ninguna de las academias propuestas tuvieron éxito, se

9 Tanck, Educación, pp. 463-508.

10 Ibid., p. 139. demostró que los profesores, a través de estas orientaciones, habían hecho explícito su deseo de cerrar filas, habían reafirmado un sentimiento de pertenecer a una comunidad que compartía una actividad común, la de educar. Probablemente el número creciente de los que competían para obtener una escuela, y el escaso número de ellas, impulsó a los maestros a tratar de limitar el número de aspirantes de algún modo. Este hecho se ve reflejado en 1853 , cuando los maestros volvieron a proponer la creación de la Academia de Profesores en la ciudad de México. Como "sociedad en clase de socios propietarios", la Academia se interesaba en examinar a los individuos de ambos sexos que quisieran adoptar la profesión, aun cuando el Ayuntamiento tuviera la última palabra en la cerrificación del profesor. A pesar de esto, la Academia insistió en hacer una selección previa de los que solicitaban ser maestros, lo cual probablemente permitía la protección de los socios propietarios. Incluía, además, en sus artículos constitutivos, la creación de un fondo común para el auxilio de las familias de los docentes y la obligación de que ningún maestro tuviera una escuela sin ser examinado. ${ }^{11}$

La tendencia, al parecer, era la misma que la de las iniciativas anteriores, cerrar para los candidatos de afuera los beneficios económicos y sociales que entraban en juego. Evitar la competencia de esta manera convertía a los eliminados en aspirantes o interesados y no menoscababa el sentido liberal de la profesión docente.

${ }^{11}$ Dublán, Colección, 1908, t. vI, pp. 353-354. 


\section{El Ayuntamiento liberal}

Una vez restaurada la república, la gestión educativa del Ayuntamiento de la ciudad de México quedó sujeta por ley a la creación y sostenimiento de escuelas gratuitas y a expedir los títulos de los profesores municipales. Se esperaba que el municipio administrara, vigilara y fomentara la instrucción primaria gratuita y que abriera un número progresivo de escuelas de acuerdo con los habitantes de la capital. La puesta en marcha de la ley de 1867 exigía que, para iniciar su gestión, el municipio contara con 24 planteles: doce escuelas para niños y doce amigas para niñas. La instancia encargada de llevar a efecto lo dispuesto por la ley sería la Comisión de Instrucción Pública, la cual echó mano de las diez escuelas municipales que venían funcionando durante el imperio.

El nuevo panorama se presentaba poco alentador, pues el municipio se hallaba en bancarrota; a los maestros se les debían cantidades considerables por sueldos devengados y lo mismo podía decirse de las deudas por concepto de renta de las casas que ocupaban los establecimientos educativos. En este escenario, los profesores pertenecientes a la Academia de 1853 se acercaron al Ayuntamiento pidiendo protección y ratificando a la Comisión como autoridad inmediata que expedía los títulos de preceptores, y vigilaba el desempeño de las escuelas de la ciudad. Sin embargo, bajo la nueva normatividad, el Ayuntamiento liberal había perdido la función de supervisar las escuelas privadas, y su acción quedaría restringida a sus propios planteles. Es por ello que la Comisión se dirigió a los preceptores municipales que habían trabajado durante el imperio y acreditó la presencia de los mismos en el ramo, a la vez que estipulaba:

En virtud del buen resultado de las tareas escolares del año que está terminando, de la indulgencia con que el $\mathrm{C}$. presidente vio al profesorado de instrucción primaria al retirarse de la capital, declarando por ley que no estaba comprendido en el delito de infidencia y que en vista sobre todo de la bondad del Ayuntamiento y su notoria justicia, se pagarán los alcances de los profesores y profesoras municipales sin rebajo alguno, librándolos de entrar en remate, pero en abonos de 25 pesos mensuales que recibirán además de su sueldo. ${ }^{12}$

Por lo menos 40 solicitudes de profesores de primeras letras fueron presentadas entre 1868 y 1871 al Ayuntamiento, esperando encontrar una plaza vacante en las escuelas. ${ }^{13}$ Las expectativas de los profesores con respecto a la educación municipal eran muy amplias, pues representaba para los docentes un empleo muy atractivo: un sueldo de 50 pesos mensuales, la posibilidad de tener casa -pues la escuela era a la vez la habitación del director-y, además, la de gozar de algunas prestaciones, como licencias con y sin sueldo. Para el Ayuntamiento, el costo de estos beneficios representó $55 \%$ del presupuesto disponible para el rubro educativo correspondiente al año de 1869; un año después esta cifra se elevaría a $60 \%$ para llegar, en 1871 , a $62 \%$, debido a la apertura de

12 Archivo Histórico del Distrito Federal (en adelante AHDF), Instrucción pública en general, vol. 2482, exp. 791 (1868).

${ }^{13}$ Ibid., vols. 2482-2484 (1868-1871). 
nuevos establecimientos, la consiguiente contratación de más maestros y al pago de sueldos atrasados. ${ }^{14}$

Un ejemplo de la gran demanda que tuvieron los empleos de profesor municipal, se puede apreciar en la queja de José Clemente Neve, un maestro que solicitó durante varios años la plaza y exponía un argumento cuya contundencia es evidente:

$[\ldots]$ y los que tenemos escuelas particulares carecemos del fruto de nuestra industria porque el preceptor municipal disfruta de su sueldo y habitación, [...] lo cual no puedo hacer yo, pues no alcanza el producto para mi manutención. ${ }^{15}$

Para la Comisión de Instrucción Pública hacer corresponder las plazas de preceptor vacantes con el número de solicitudes implicaba un problema de asignación, en el sentido de que tendría que definir quién debería ocupar el puesto, cómo y por cuánto tiempo. Finalmente, el Ayuntamiento monopolizaba la disposición sobre los beneficios de la educación municipal (sueldo, casa y prestaciones), pero se trataba de bienes escasos que enfrentaban una gran demanda.

Una de las medidas que tomó la $\mathrm{Co}-$ misión fue admitir en el ejercicio magisterial a sólo aquellos que cumplieran con ciertos requisitos:

No podrá conferirse en lo sucesivo el empleo de directores o directoras de las escuelas municipales, sin haber probado, quien

14 AHDF, Memoria del Ayuntamiento, 1870 , pp. 7-9.

${ }^{15}$ AHDF, Instrucción pública en general, vol. 2483 , exp. 807 (1870). lo solicitare ante la Comisión de Instrucción Pública y a satisfacción de ésta, que posee los conocimientos [necesarios] para la educación primaria. ${ }^{16}$

El problema de la sobredemanda se resolvía con las pruebas de aptitud para entrar a la comunidad de profesores municipales. Ciertamente jugaba un papel importante el interés de los propios maestros ya instalados en las escuelas para que, sin perjuicio de la competencia, se asegurara su estabilidad en el empleo. Para ello, en 1871 la Comisión de Instrucción Pública decidió que los exámenes de oposición fueran calificados por aquellos maestros que gozaban de mayor reconocimiento. ${ }^{17}$ Con ello, dicha Comisión daba cauce al trámite de expedir o no el título de preceptor de primeras letras sin interferir en la comunidad, y el Ayuntamiento afianzaba su posición como otorgador de empleo, casa y prestaciones.

Sin duda, depurar el proceso de reclutamiento y selección de profesores confería al municipio prestigio y autoridad. La oportunidad fue reconocida y puesta en marcha por el Ayuntamiento que decidió crear la Escuela Central en 1872, la que, entre otras cosas, pretendía ser una Normal para profesores:

Para formar maestros instruidos ya han puesto en juego quienes deben y pueden los medios conducentes: fundación de planteles, recursos, vigilancia, reglamentación, severidad al otorgar los títulos. Adquiere un joven en la escuela de su barrio el canal de conocimientos que la ley exi-

${ }^{16}$ Ibid., exp. 890 (18970).

17 AHDF, Instrucción pública en general, vol. 2484, exp. 930 (1871). 
ge, demuestra su ciencia en el severo y concienzudo examen hecho por jueces idóneos y bajo inspección de la autoridad recibe la investidura de un sacerdocio y comienza a ejercerla. ¿Habrá de entregarse al nuevo maestro la generación nacional en plena confianza en el buen éxito? El maestro no necesita sólo de su ciencia, sino saber transmitirla. Sin el conocimiento de las facultades del hombre y de la manera con que se desarrollan, sin el estudio de los medios más a propósito para encaminar recta y suavemente su perfección esas facultades del maestro caminarán a ciegas, consumirá su vida en inútiles esfuerzos y a falta de una acción inteligente y fecunda echará mano de la estéril rutina. ${ }^{18}$

Además de formar profesores, la nueva escuela ofrecería clases nocturnas para adultos y buscaría "atraer a los niños de clase media que muchas veces no tienen dónde educarse por falta de recursos", poniendo a disposición materias como inglés, francés, retórica, grabado en madera, música, taller de doraduría, dibujo natural, costura, flores artificiales y canto. ${ }^{19}$ Como la Comisión alegaba que el proyecto era costoso, se suprimirían catorce establecimientos municipales, y 33 planteles se especializarían en instrucción rudimientaria donde se enseñaría solamente a leer, escribir y las cuatro operaciones de aritmética para los alumnos que quisieran recibir educación en corto tiempo.

Con la nueva Escuela Central, el Ayuntamiento podía llevar a cabo un proceso de capacitación de profesores que después cubrirían las plazas de to- dos los planteles de la capital, incluyendo las cuatro escuelas que sostenía el gobierno federal, los planteles municipales, además de habilitar maestros que "pudieran esparcirse por los estados de la república". ${ }^{20} \mathrm{Si}$ el municipio capitalino contaba con un centro educativo de esta naturaleza se convertía en el proveedor más importante de docentes y ofrecería educación gratuita de calidad para alumnos de todo el país. Con ello, su legitimidad social y política se afianzaba.

Para el 5 de mayo estaba previsto que se inaugurara la Escuela con la presencia del presidente de la república, pero esto no sucedió. En cambio, el Ayuntamiento fue objeto de una fuerte presión política. Ejemplo de ello es una carta de los padres de familia oponiéndose a la supresión de planteles:

En nuestra época creemos que es absolutamente necesaria la instrucción primaria y no se reduce simplemente a saber leer y escribir. Si recapacita, será usted el benefactor del pueblo, de lo contrario, tendremos el grande sentimiento de que nuestros hijos no reciben el bien de nuestros dignos representantes e irán a recibirlo a donde la filantropía nos tienda su mano bienhechora. ${ }^{21}$

En 1872 buscar la educación en la filantropía significaba acudir a las escuelas que auspiciaba la Iglesia, y esto se oponía a la instrucción laica que profesaba el Estado. La presión ejercida sobre la Comisión surtió efecto, pues en julio de ese año "circunstancias demasiado graves" obligaron a clausurarla.

$20 \mathrm{Ibid}$.

${ }^{21}$ Ibid, exp. 995 (1872). 


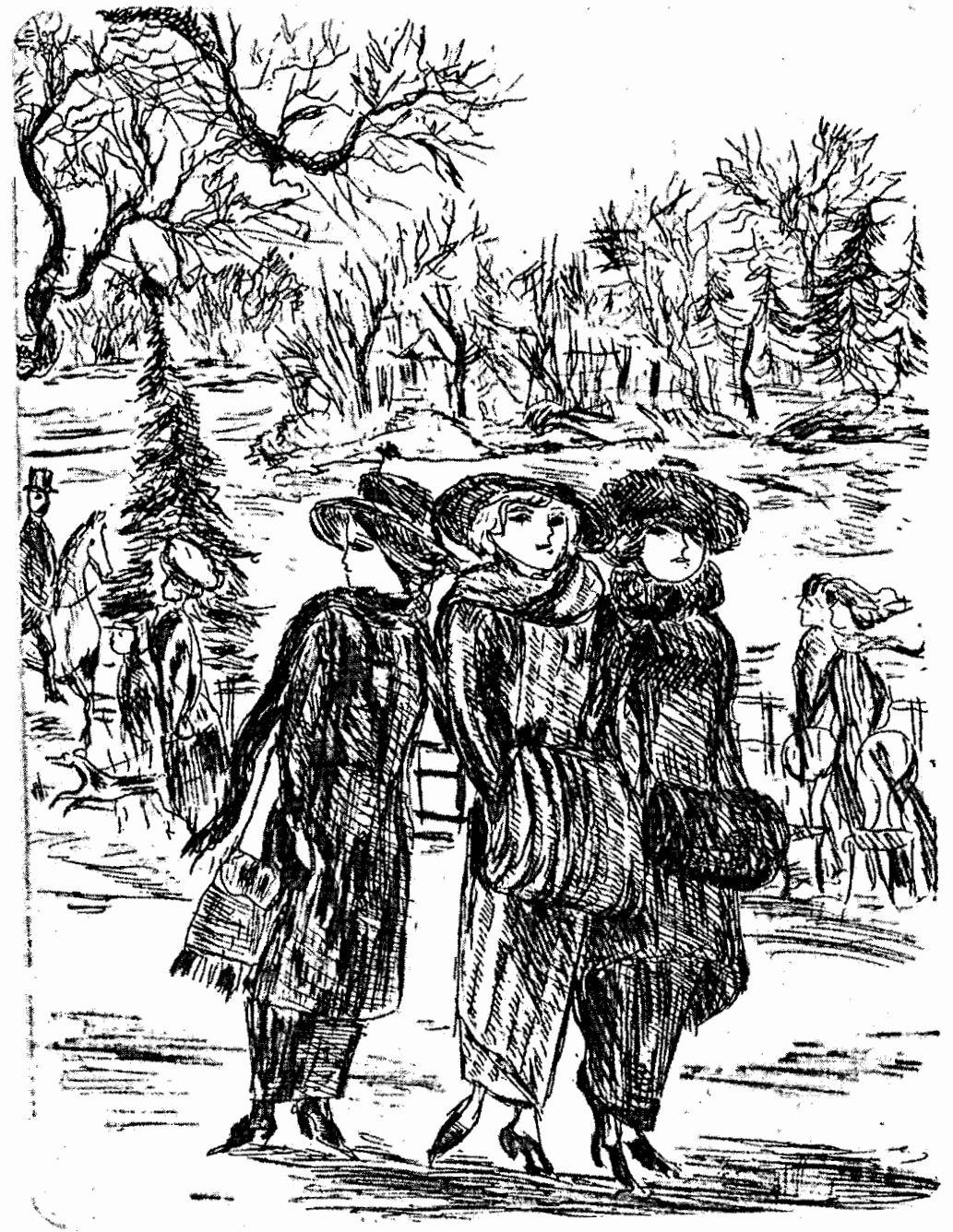


Es claro que el Ayuntamiento había traspasado el rango de su jurisdicción, pues entró en un terreno que, a partir de 1867 , pertenecía al proyecto educativo federal. El propio presidente Juárez dirigió una carta al municipio que marcaba los límites de su actuación:

El gobierno hace justicia a la corporación municipal en cuanto al móvil que la guió en la creación de ese establecimiento, pues con él quiso sin duda llenar uno de los grandes vacíos que tenemos todavía en la instrucción que es el de la escuela para formar profesores aptos, que por sus dotes intelectuales y morales puedan ejercer con toda conciencia el alto magisterio de la educación del pueblo; aplaude su celo pero no puede sostener lo que no está conforme con las prescripciones de la ley. La necesidad de la Escuela Normal el gobierno la satisfará reglamentándola y pidiendo al Congreso en su próxima reunión la aprobación de los gastos que demanden su creación y su sostenimiento, con el cual quedará satisfecho el deseo del Ayuntamiento y cubierto de una manera legal el vacío antes indicado. [...] No ha habido pues razón legal ni de conveniencia para la supresión de esas escuelas, tanto más cuanto que no se puede ni siquiera alegar por ello la falta de recursos, puesto que los que servían para sostenerlas se emplearon actualmente para el sostenimiento de la Escuela Central. Al Ayuntamiento por la ley solo le está encomendado cuidar de la instrucción primaria en los términos que el reglamento de esa misma ley designa. ${ }^{22}$

El enfrentamiento entre los dos niveles de gobierno, el federal y el local, esta-

${ }^{22}$ Ibid., exp. 1008 (1872). ba relacionado con las expectativas de cada uno de ellos. Mientras que para el gobierno federal el objetivo era ampliar su rango de acción más allá del Distrito Federal y territorios y lograr la uniformidad educativa en el país; para el Ayuntamiento, en cambio, cubrir los costos de la educación en la ciudad le daba la posibilidad de allegarse nuevas funciones: crear una opinión pública favorable y obtener mayor presencia en las decisiones políticas. El resultado de dicho enfrentamiento fue que el Ayuntamiento, a través de la Comisión de Instrucción Pública, volvió a concentrarse en administrar los establecimientos municipales, en crear un número progresivo de escuelas de acuerdo con los habitantes de la ciudad y en expedir los títulos de preceptor municipal.

\section{LA ESTRUCTURA MAGISTERIAL}

Para 1877, la capital contaba con 56 planteles municipales. A lo largo de diez años, el Ayuntamiento había abierto 32 establecimientos. No obstante, sólo en el último año más de 60 solicitudes por escrito habían llegado a manos de la Comisión pidiendo la dirección de algún plantel. La demanda de empleo se había convertido en una preocupación recurrente para el municipio,

pues no faltan personas de entre las cuales pueda escoger: multitud de solicitudes oficiales [sic] se han presentado al Ayuntamiento sobre esas plazas y multitud de recomendaciones particulares de personas que desean obtenerlas se han dirigido a los individuos de la Comisión. ${ }^{23}$

${ }^{23}$ Ibid., vol. 2487, exp. 1259 (1877). 
El número creciente de las solicitudes para ocupar una plaza de profesor en comparación con las posibilidades de obtenerla acrecentó el interés de la autoridad por limitar de algún modo el número de interesados. Para ello, se estableció un ordenamiento que exigía ciertos requisitos mediante los cuales la Comisión pudo limitar la demanda; para ser director de una escuela municipal el candidato debía ser mexicano de nacimiento o por naturalización, tener cuando menos 29 años de edad si era varón, y 18 si era mujer, presentar título de profesor de instrucción primaria acreditado por el municipio y "acreditar su moralidad y buenas costumbres suscritos por dos o más personas fidedignas". Además, se exigía un año previo de práctica. ${ }^{24}$

La mayor dificultad que enfrentaba el Ayuntamiento era la asignación de un gran número de profesores aspirantes en las pocas plazas vacantes. No sólo no se habían abierto suficientes establecimientos para atender la creciente demanda de empleo, sino que la planta de maestros había permanecido prácticamente estable a lo largo de diez años. De los 24 maestros que habían iniciado en 1868 , algunos de ellos heredados desde el imperio, cinco habían muerto y dos más habían renunciado. En realidad, en esos diez años, el municipio había empleado a 49 profesores, pero había expedido títulos (sólo en 1877) a 58 señoritas y a siete jóvenes que esperaban su turno para ingresar como directores. ${ }^{25}$

\footnotetext{
24 Ibid.

${ }^{25}$ Los profesores que fallecieron fueron: Agustín Canta la Piedra en 1870, Mariana Torija en 1871, Rosa Rodríguez Puebla en 1868, Mendoza Hurtado en 1870, Trinidad Herrera de Fontana en
}

El problema no era menor, pues al no abrirse los puestos para maestros podía perder valor el título de profesor municipal y, peor aún, la demanda externa presionaba a la comunidad docente que no estaba dispuesta a perder sus privilegios.

¿De dónde provenía la fuerza de los directores? Sin duda, los profesores validaban su actuación en el barrio o en la manzana donde la escuela se encontraba; de esta forma, quien lograba establecer una relación de proximidad con los vecinos tenía asegurado un lugar como maestro. El profesor municipal participaba en el vecindario y era parte de él, por lo menos mientras el crecimiento urbano permitió mantener la cercanía vecinal. El trabajo de docente garantizaba el desarrollo de una carrera profesional; la continuidad en el desempeño del cargo hizo que muchos maestros ejercieran la misma rutina en las mismas escuelas y en el mismo barrio, durante muchos años. En ocasiones, los vecinos intercedieron para impedir la remoción de maestros o que no se les trasladara a otro lugar de la ciudad. Existe una gran variedad de cartas enviadas al Ayuntamiento y al gobierno del Distrito Federal para interceder por los profesores. Basten por ahora sólo algunos ejemplos:

En 1877, los vecinos de San Cosme pidieron que no se cambiara a la directora de la amiga número 15 , pues “[...]

1870. Los profesores que renunciaron fueron: Luis Álvarez y Guerrero y Trinidad Bernard. Las causas de las renuncias fueron porque no les parecieron las condiciones de las escuelas de las parcialidades. Véase AHDF, Instrucción pública en general, vols. $2482,2483,2484$ y 2485 . 
con su trato paciente y finos modales, y su empeño para el cumplimiento de sus obligaciones ha sabido captarse la buena voluntad de las educandas y de sus padres y madres". La carta tenía un tono de advertencia, ya que aseguraba que si se cambiaba a la maestra, "quedaría abierta la puerta a las faltas de asistencia que trajese consigo el disgusto de las niñas y del de sus autores de sus días". ${ }^{26}$

Los vecinos de los cuarteles II y IV expresaron ante la Comisión su punto de vista:

sabedores de que el presidente del Ayuntamiento, atendiendo a la aptitud del $\mathrm{C}$. profesor José Refugio Vallejo, va a nombrarlo director de una escuela municipal suplican interponer su influjo a fin de que lo sea de la que se halla en la segunda calle de la Amargura número 5. El C. Vallejo es perfectamente conocido en el barrio a causa de haber tenido un establecimiento particular $[\ldots]$ en el que se educaron muchos jóvenes que le honran por sus conocimientos y finos modales y al que los pobres no mandaban a sus hijos por carecer de recursos. ${ }^{27}$

Para bien o para mal, los vecinos podían determinar la suerte de un maestro. Sobre todo, podían destituirlo si se consideraba ajeno a los intereses del barrio.

${ }^{26}$ Ibid, vol. 2484, exp. 952; vol. 2485, exps. 1020 y 1029.

27 Ibid., vol. 2485, exp. 952 (1872). En otra carta se pide al gobierno del D. F. dé marcha atrás a la resolución del Ayuntamiento de cambiar al director de lugar "pues así como él ve a nuestros hijos como suyos, nosotros vemos sus intereses como nuestros". Ibid., exp. 1029.
En los pueblos éste era un recurso utilizado cuando las comunidades de las parcialidades de indios, ubicadas en las afueras de la ciudad, veían como extraño o impuesto a un preceptor que venía de la ciudad. En 1887, Vicente Blasio, profesor del pueblo de la Resurrección durante 17 años, fue acusado por los vecinos ante el Ayuntamiento de ineptitud. Para Blasio tal acusación respondía a un ardid tramado por Corona, que era el cacique del pueblo, para destituirlo, por lo que suplicó a la Comisión de Instrucción Pública hacer una investigación de su caso antes de proceder a su destitución. De acuerdo con las indagaciones había declaraciones contradictorias entre los vecinos, lo que hace pensar que era Corona quien no admitía al profesor. Se desprendió de las averiguaciones que el maestro de la escuela se había hecho de terrenos en el pueblo, en los que cultivaba alfalfa, lo cual era probablemente la causa de la molestia de Corona, quien había movilizado a los vecinos para removerlo del pueblo. Blasio demostró ante el Ayuntamiento su historial de reconocimientos y menciones honoríficas por su labor en el municipio, pero el poder del cacique fue superior y el preceptor fue destituido del cargo. ${ }^{28}$

Dada esta situación, para contratar nuevos profesores, sin dañar los intereses de los profesores ni de los vecinos, la

${ }^{28}$ Después de retirar a Blasio del cargo, Corona donó ropa para los niños pobres de la escuela. La carta de los vecinos y las averiguaciones de la $\mathrm{Co}-$ misión se encuentran en AHDF, Instrucción pública en general, vol. 2498, exp. 2152 (1887). Se pueden encontrar otras referencias similares en Lira, Comunidades, 1983, pp. 243-262. 
Comisión decidió acreditar la incorporación de docentes mediante un estricto examen de oposición que incluía una disertación escrita, una exposición oral y un ejercicio práctico designado a suerte. Dicho examen sería calificado por un jurado compuesto de cinco profesores municipales (todos varones) y un miembro de la Comisión que no tendría voz ni voto. Lo sorprendente vuelve a ser que el proceso de selección aseguraba la cohesión de la comunidad, pues éste quedaba en manos de los mismos profesores.

El cambio político que se registró en la república en 1876 cooperó con el proyecto de ampliación de la comunidad magisterial. Porfirio Díaz había desconocido al gobierno del presidente Sebastián Lerdo de Tejada por abuso de autoridad, y dispuso el cese de todos los empleados y funcionarios del gobierno, lo que afectó a los empleados del municipio incluyendo a los profesores. La circunstancia de haber renunciado los directores a sus empleos, en virtud del decreto del 26 de noviembre de 1876 y la promulgación de los planes de Tuxtepec y Palo Blanco, hacían más fácil la tarea de incluir en los beneficios asignados a la docencia municipal a más maestros. En 1877, los viejos directores fueron rehabilitados, es decir, legitimados en sus puestos, jurando lealtad a la Constitución de 1857 y a sus reformas. Ese mismo juramento fue hecho por algunos maestros interinos, que no habían podido conseguir el cargo ni los beneficios correspondientes al mismo.

No se tiene referencia de los exámenes realizados entre 1877 y 1887 , en cambio, los que ingresaron a la comunidad magisterial fueron los maestros que ya habían trabajado supliendo algunos directores en sus puestos. ${ }^{29}$ Nuevas ventajas económicas se crearon posiblemente con el propósito de garantizar la continuidad de la actividad del profesorado, entre ellas, el empleo de preceptor de instrucción primaria municipal, alcanzado legítimamente (por rehabilitación), era a perpetuidad, revocable sólo por incapacidad intelectual, inmoralidad o por delitos de orden común. Asimismo, el Ayuntamiento otorgaba licencia por enfermedad con la mitad de sueldo hasta por seis meses. En caso de fallecimiento, después de dos años de servicio, se pagarían 100 pesos para gastos de inhumación y por cada diez años de servicio se otorgaría un diploma. ${ }^{30}$

Con la nueva reglamentación el municipio aseguraba una red clientelar, pues reiteraba su interés en ser el proveedor de beneficios económicos en torno a una comunidad que, a partir de entonces, se podía sentir más segura. Por un lado, su presencia estaba legitimada en un nuevo escenario político y, por otro, se limitaba la competencia que representaba la demanda exterior, al estipular que los directores eran propietarios de sus puestos.

\section{LA CIUDAD Y SUS RETOS}

Esta estructura, sin embargo, no sería viable en la década de los ochenta. En esos años, la ciudad registró un movi-

29 Los profesores interinos que ingresaron en la comunidad fueron, Fernando Rodríguez, José Lazcano, Victoria Colard, Adelaida Sophy, Natalia Morales y José Lizárraga. Véase AHDF, Instrucción pública en general, vol. 2487, exp. 1303 (1877). 30 Ibid. 
miento poblacional sin precedente, fuertes corrientes migratorias influyeron en la disposición del espacio y en todos los ámbitos de la vida urbana. ${ }^{31}$ Las aulas se llenaron y se hizo necesario crear más escuelas. Para atender al crecimiento de la población, el Ayuntamiento diversificó la oferta educativa. Se abrieron escuelas elementales mixtas, además de las escuelas para varones y de las amigas para mujeres; de 55 planteles que había en 1877, para 1886 la municipalidad de México contaba con 91 establecimientos de instrucción primaria. ${ }^{32}$ Los planteles prácticamente se duplicaron; no obstante, el aumento se hizo con base en la supresión de algunas amigas municipales, de las cuales se crearon - por cada amiga clausurada-, dos escuelas elementales mixtas. Como la Comisión alegaba falta de fondos, las elementales fueron presididas por maestras, a las cuales se les asignó la mitad de sueldo (25 pesos), y de esta manera se escindió al profesorado femenino en dos categorías: las que percibían el sueldo completo y que tenían el puesto de directoras de amigas y las que sólo contaban con la mitad de la remuneración a cargo de las elementales. Fue tal la afluencia de niños y niñas en las escuelas que algunos planteles reportaron en esos años una asistencia promedio de 100 alumnos o más, lo que derivó en la contratación de ayudantes y auxiliares para facilitar

31 Véase Gortari y Hernández, Ciudad, vol. III, 1988, pp. 285-287. Algunas interpretaciones sobre los censos también se encuentran en Rodríguez, Experiencia, 1996, pp. 81-104.

32 AHDF, Memoria del Ayuntamiento, 1882, pp. $15-18$. el desempeño de cada director o directora. 33

El crecimiento acelerado de la educación municipal había modificado la composición de la comunidad magisterial. Con el nuevo personal surgieron jerarquías económicas y los beneficios se convirtieron en una prerrogativa de los profesores con más antigüedad en el puesto. Uno de éstos fue la perpetuidad en el empleo, que era un derecho para los directores y directoras, no así para los ayudantes y auxiliares:

Cuando un director sabe que su empleo está sujeto a las eventualidades del cambio periódico en el personal del Ayuntamiento, a la mala voluntad o capricho de alguno de los comisionados de instrucción pública, o al influjo de una recomendación superior; no.tiene estímulo en sus labores, ni procura con empeño el adelanto de su establecimiento, ante la consideración de que serán inútiles los esfuerzos que haga, puesto que el favoritismo o cualquiera otra causa innoble puedan arrebatarle un empleo cuyo buen servicio consagró todos sus desvelos y los mejores años de su vida. ${ }^{34}$

Los ayudantes fueron nombrados por el Ayuntamiento, pero a propuesta de una terna que presentaba el director o la directora; los auxiliares necesitaban ser mayores de quince años y tener regular instrucción a juicio de los mismos. ${ }^{35}$ El derecho de nombrar la terna de ayudantes propició que muchos de los di-

33 Ibid.

${ }^{34}$ AHDF, Instrucción pública en general, vol. 2494, exp. 1795 (1884).

${ }^{35} 1$ bid. 
rectores tuvieran contratados a sus propios familiares. Sin embargo, en 1884 la Comisión dispuso que los ayudantes tenían que ser profesores titulados, aceptando con ello la demanda de maestros titulados por el mismo Ayuntamiento que esperaban turno para entrar en las escuelas municipales. ${ }^{36}$

Hacia mediados de la década de los ochenta, se había consolidado una estructura jerarquizada, de tipo piramidal, al interior de la comunidad de maestros. Aunque todos los profesores debían estar titulados, los directores y directoras más antiguos gozaban de grandes beneficios: los directores contaban con un sueldo de 60 pesos libres al mes, lo que en términos reales era una remuneración mayor, ya que no pagaban renta de la casa en que habitaban, pues era la misma donde se ubicaba la escuela. Además, un director podía disponer del inmueble a su entera satisfacción, destinando sólo una pieza al aula de clases y las demás habitaciones para su uso personal y familiar. ${ }^{37}$ Entre sus prestaciones se incluía una licencia hasta por tres meses con goce de sueldo en caso de enfermedad justificada y jubilación a

${ }^{36}$ Desde 1881, el Ayuntamiento había expedido 44 títulos para profesoras y seis para profesores. Para 1885 se sumaron a los profesores titulados 48 señoritas más y dos señores. Véase AHDF, Memoria del Ayuntamiento, 1881-1885.

${ }^{37}$ En 1883, el regidor del Ayuntamiento hacía el siguiente comentario: "Las casas en que están ubicados los planteles son [...] muy reducidas; y si se atiende a que los profesores toman las tres cuartas partes de las casas para sus habitaciones particulares, resulta que los niños se ven confinados a espacios muy reducidos". Véase AHDF, Memoria del Ayuntamiento, 1883, p. 17. partir de los quince años de servicio. Los directores y directoras de los planteles contaban con la ayuda del Ayuntamiento en caso de enfermedad o de muerte de algún familiar, y algunos de ellos tenían la opción de un sobresueldo de 25 pesos mensuales dando clases a adultos por las noches. ${ }^{38}$ En un segundo plano, dentro de la jerarquía, estaban las directoras de las amigas municipales que recibían 50 pesos de sueldo y los mismos beneficios sobre la habitación que los directores, incluyendo las clases nocturnas como compensación para las maestras más prestigiadas. Un tercer nivel lo conformaban las directoras de las escuelas elementales que, si bien contaban con un título de profesoras, sólo alcanzaban la mitad de las prestaciones consideradas a los anteriores, sueldo de 30 pesos y casa. Por último, estaban los ayudantes con un sueldo de 25 pesos, quienes buscaban un interinato sin ningún otro beneficio asociado al puesto, para escalar a la categoría de director.

La jerarquía interna de la planta magisterial estaba condicionada en un primer término, por el factor género; en una segunda instancia, por el mérito académico y, finalmente, por la antigüiedad. Los directores más reconocidos obtuvieron ingresos superiores a los que percibían el resto de los profesores municipales, además de que su prestigio y experiencia los colocaba en un lugar privilegiado en la ciudad. Para ello, los exámenes públicos anuales eran los espacios en los que, en presencia del presidente de la república, el director demostraba

${ }^{38}$ AHDF, Escuelas nocturnas, vol. 2567, exp. $16(1871)$. 
que sus alumnos podían leer, recitar de memoria las lecciones y escribir. Con gran notoriedad pública, los alumnos recibían medallas de oro, plata y bronce o, en ocasiones, juguetes. El director, a su vez, era premiado con dinero en efectivo y compensaciones económicas. Con ello no sólo acumulaba ingresos, sino méritos que lo colocaban en una mejor posición en relación con otros maestros.

A manera de ejemplo, para entender los beneficios asignados de acuerdo con el mérito de los profesores, resulta interesante seguir la trayectoria de Carlos María Aranda. En 1886, Aranda tenía a su cargo una escuela municipal y se convirtió en el director más reconocido para el Ayuntamiento desde 1869. Había sido empleado en un almacén de comercio donde llevaba libros de cuentas, facturas y correspondencia, lo que aprovechó para dar clases especiales a los niños y aumentar el número de materias, colocando a su escuela como una de las más apreciadas por los vecinos. Los mismos profesores manifestaban que el primer premio en los certámenes públicos anuales lo tenía asegurado la escuela número 1 que manejaba Aranda, pues era "verdaderamente la primera, tanto por sus brillantes resultados que desde su creación ha dado, como porque en ella se enseñan ramos superiores que en ninguna otra". ${ }^{39}$ Como el director más antiguo del municipio, los vecinos lo consideraban "un hombre amigo del pueblo, amante del pobre". ${ }^{40}$ El Ayuntamiento trató de compensar su sueldo, por lo que

39 AHDF, Instrucción pública en general, vol. 2485, exp. 1017 (1875); vol. 2483, exp. 879 (1870).

40 Ibid., exp. 1029 (1872). en 1870 lo nombró director de una escuela nocturna, lo que representaba una remuneración adicional de 25 pesos al mes y, en 1877 , le dio el encargo de distribuir los útiles escolares con un sobresueldo de quince pesos. Sin embargo, la capacidad de Aranda tenía límites y no podía cumplir con sus funciones de visitador recorriendo 58 escuelas mensualmente, y a la vez continuar con sus propias labores, por lo que el puesto quedó suspendido. ${ }^{41}$ En 1882 Aranda fue nombrado miembro de la comisión dictaminadora del Congreso Higiénico Pedagógico. ${ }^{42}$ Las escuelas que presidió obtuvieron siempre el primer premio, lo que le significó, para dicho profesor, una remuneración adicional al final del año entre 100 y 200 pesos, además de reconocimientos honoríficos como diplomas y medallas.

Otro profesor, Andrés Oscoy, fue quizá el director con una trayectoria más larga en el municipio. Insistió, desde 1877, para obtener una plaza de director y fue uno de los profesores que consiguió el puesto en el momento en que la planta de maestros se abría por el cambio político del que ya hemos hablado. Doce años después, tenía a su cargo la escuela municipal más grande, la que contaba con 560 alumnos -cuando el promedio era de 100-; tenía a su disposición a siete ayudantes (dos de los cuales eran sus familiares) y dos auxiliares; y percibía un sueldo de 900 pesos anuales. ${ }^{43}$ Oscoy fue nombrado representante de las escuelas municipales para asistir

${ }^{41}$ Ibid., vol. 2487, exp. 1254 (1877).

42 Véase Liceaga, Recuerdos, 1949, p. 186.

${ }^{43}$ AHDF, Instrucción pública en general, vol. 2494, exp. 1831 (1885). 
al Congreso Pedagógico en 1889 y se hizo cargo de una escuela nocturna en la década de los noventa, aumentando sus ingresos con 50 pesos mensuales. A diferencia de los demás profesores, Oscoy logró su fama como director siendo muy joven, lo que probablemente le permitió capitalizar su prestigio. En los últimos años de la década de los noventa publicaba en su imprenta la Crónica de las oposiciones para proveer de director las plazas vacantes del municipio. Cada ejemplar valía 25 centavos y se podían encontrar en él, "todas las cuestiones formuladas por el regidor y los profesores que estuvieron en turno en los certámenes". ${ }^{44}$ La fama de Oscoy siguió más allá de finales de siglo, ya que en 1907 fue el encargado de hacer el libro Elocuencia y poesía castellanas para la Escuela Normal de Profesores. 45

Se podrían citar más ejemplos, pero el desempeño de Aurelio M. Oviedo muestra hasta qué punto los maestros compitieron entre sí para lograr los privilegios que confería el Ayuntamiento. Oviedo fue nombrado junto con Oscoy representante ante el Congreso Pedagógico en 1889, su prestigio declinó cuando perdió el primer lugar en los exámenes finales y decidió, junto con su hijo que era su ayudante, aprovechar su experiencia y fundar una escuela particular haciendo uso del reconocimiento logrado en el municipio durante siete años. En la carta que Oviedo remitió a la Comisión de Instrucción Pública puede apreciarse no sólo las ventajas que obtenía un profesor al ser reconocido por

${ }^{44}$ Ibid., vol. 2510, exp. 2987 (1895).

45 Bazant, Historia, 1995, p. 152. el Ayuntamiento, sino el costo que implicaba, para los mismos profesores, perder esos privilegios:

Hago formal renuncia a la dirección de la escuela municipal número 3 , que por más de siete años ha sido a mi cargo dando las debidas gracias al Ayuntamiento por tantos favores y distinciones que me ha colmado. La aceptación como libro de texto en sus escuelas de mis libros de lectura; 100 pesos mensuales para renta de la casa que ocupaba, cuando la mayor parte de las escuelas no costaban más de 50 ; la honra de contar mi personalidad cuando se ha tratado de reformas en los reglamentos entre los pocos profesores con quienes se ha consultado y disentido. Son distinciones exquisitas que jamás olvidaré y que siempre he reconocido procurando corresponder a ellos de cuantos modos he podido: no molestando jamás para que se repusiese ni un ladrillo de los pisos, lo cual así como la decoración de las paredes y reposición de vidrios se ha hecho siempre de mi cuenta: manteniendo en los últimos años ayudantes y profesores a mi costa: trabajando los domingos en enseñar a los niños el dibujo, y velando por la noche para que los resultados fuesen satisfactorios para la $\mathrm{H}$. Corporación que me honraba con su confianza [...] Año con año, sin faltar uno, he sido agradecido con el primer premio siempre que lo ha habido, excepto el último, para el que se tuvo a bien tomar como criterio otro punto de partida presupuestal que no estuvo en mi mano contestar. 46

${ }^{46}$ AHDF, Instrucción pública en general, vol. 2498, exp. 2152 (1887). 


\section{LA COMUNIDAD DE PROFESORES}

La actuación de los profesores municipales, por su parte, hace pensar que su interés estaba enfocado en perpetuar sus prerrogativas; es decir, buscar las ventajas económicas y mantener regulado el acceso a los beneficios a través de una estructura heterogénea y jerárquica. Una muestra de ello fue la creación en 1885 de la Academia Municipal de Instrucción Pública. Dicha Academia tenía por objeto,

formar de los profesores municipales un cuerpo unido y respetable, mejorar cuanto sea posible todo lo relativo a las escuelas y amigas municipales de la capital y prestar apoyo moral y auxilios mutuos a los miembros de la Academia en todas las circunstancias de la vida. ${ }^{47}$

La organización reafirmaba el sentido de comunidad casi gremial de los docentes municipales y a la vez legitimaba la jerarquía interna que había entre los maestros al establecer dos tipos de socios: de número, compuesto por los directores y las directoras de las escuelas y amigas municipales; $y$ activos, formado por las directoras de las escuelas elementales, los ayudantes y demás profesores que fuesen admitidos en la Academia. Además, para ser socio activo, sin pertenecer al municipio, se requería ser postulado por dos socios de número $\mathrm{y}$ admitido por la mayoría de los presentes. Lo más interesante es que la Academia, concebida como una asociación, de-

47 lbid., vol. 2496, exp. 2020 (1885). Las cursivas son mías. legó en el administrador de rentas municipales la función de recaudador y depositario de fondos. ${ }^{48}$

La Academia Municipal garantizó la estabilidad y desempeño del profesorado durante mucho tiempo después de su creación. En 1896, cuando las escuelas pasaron al gobierno federal, Luis E. Ruiz como comisionado de Instrucción Pública explicó cuál había sido su función:

Hacen intercambios de experiencias y establecen entre ellos la solidaridad moral y para la sociedad. La Academia se constituye como una asociación cienrífica, se norman sus trabajos en general y por grupos y se ha establecido una especie de pequeña caja de ahorros que patentiza los beneficios de la unión. 49

No debe sorprender que Ruiz haya destacado el sentido de unión de los maestros, pues el mismo Ayuntamiento avalaba esta tendencia de cerrar filas que le garantizaba a la Comisión de Instrucción Pública la posibilidad de regular el acceso a los beneficios y presentarse como instancia protectora cuando los maestros veían amenazados sus intereses.

\section{LA FÁBRICA DE MAESTROS}

Una verdadera amenaza a los intereses de los profesores municipales fue la creación de la Escuela Normal. Dos años después de haber abierto la Academia Municipal, el Ministerio de Justicia e Instrucción Pública inauguró, el 24 de

48 Ibid.

49 Ibid., vol. 2512, exp. 3128 (1896). 


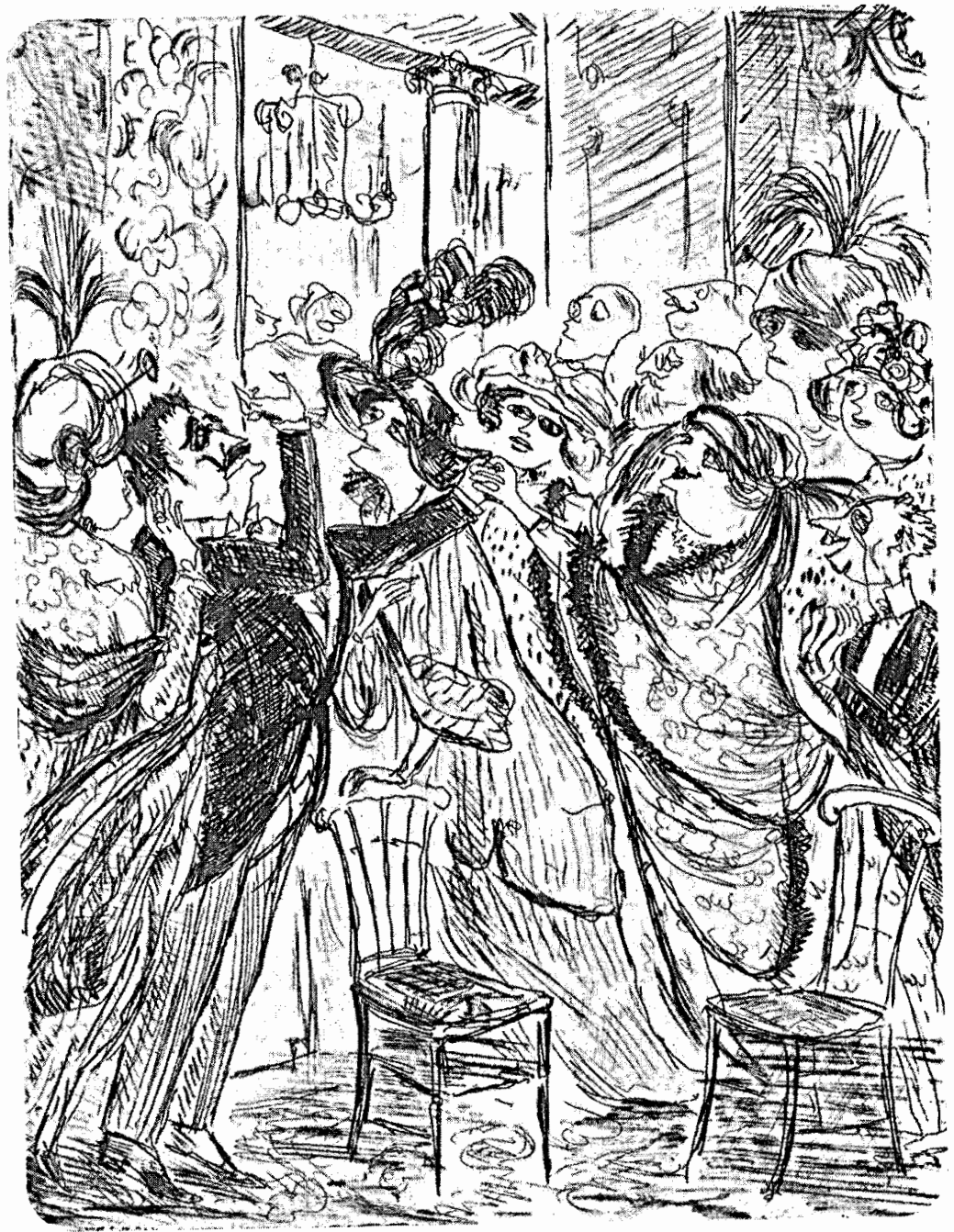


febrero de 1887, la Escuela Normal para Profesores en la ciudad de México. Creada con el propósito de uniformar la educación, la Normal sería, a partir de entonces, el modelo del cual se derivarían las demás escuelas. El meticuloso cuidado en cuanto a la selección de materias $y$ plan de estudios revelaba las expectativas que el gobierno federal había dispuesto en el flamante plantel. Entre otros logros, los futuros profesores perfeccionarían sus conocimientos y el arte de transmitirlos a través de planteles anexos que servirían para realizar las prácticas pedagógicas. La Normal capitalina se abrió sólo para varones, y no fue sino hasta 1890 que la Escuela Secundaria para Niñas -instancia encargada de preparar maestras desde mediados de la década de los setenta-, se transformaría en la Escuela Normal para profesoras. 50

Desde sus inicios, se prescribió que sólo la Escuela Normal de Profesores de la ciudad de México podía expedir los títulos de maestros y autorizar a los candidatos para ejercer la enseñanza primaria en las escuelas públicas del Distrito Federal y territorios. Además, desde el 1 de enero de 1887, las escuelas municipales se organizarían conforme a las bases establecidas por los establecimientos anexos a la Normal. Entre otros puntos, esto implicaba un aumento de $50 \%$ en el sueldo de los profesores, instalaciones especiales para las escuelas y contratación de más personal.

Al día siguiente de ser inaugurada la escuela de los futuros profesores, el título de preceptor de instrucción primaria

50 Morales, Tendencias, 1983 , pp. 315-357, y Bazant, Historia, 1995, pp. 129-157. expedido por el Ayuntamiento perdió todo valor, y con ello la capacidad de reclutamiento de la Comisión quedó sin efecto. Los primeros egresados de la Normal no saldrían hasta cuatro años después, sin embargo, a partir de 1888 la Comisión de Instrucción Pública quiso hacer pública la apertura para la consecución de plazas y poder cumplir con el requerimiento de la Normal. Fue entonces que expidió convocatorias y anunció que celebraría exámenes de oposición. En realidad, en los siguientes dos años, y hasta que terminó su gestión en 1896, el Ayuntamiento amplió la planta de maestros con profesoras egresadas de la Escuela Secundaria para Niñas, las cuales ocuparon los cargos de ayudantes y más de la mitad de las direcciones de las escuelas para varones, lo que fue una novedad.

No resulta difícil suponer que la Comisión diera cauce a los lineamientos de la Normal mediante la contratación de mujeres: por un lado, el municipio tenía la posibilidad de expedir los títulos de maestras municipales a las egresadas de la Escuela Secundaria para Niñas y podía completar su planta de docentes con maestras a través de un sistema educativo que se retroalimentara a sí mismo, sin la injerencia de la Normal y sin perder el espacio en el que mantenía su autoridad. Por otra parte, probablemente contratar a las maestras resultaba menos oneroso porque ganaban un sueldo menor. Si bien las remuneraciones de los profesores representaron para el municipio en 1887 alrededor de 50\% de la estructura del gasto en educación, esta partida no representó una erogación mayor por el solo hecho de haber contratado mujeres. 
Para principios de la década de los noventa, era claro que la instrucción primaria representaba un asunto en el cual el gobierno federal estaba dispuesto a intervenir sin dar marcha atrás. En 1891, el ejecutivo expidió la ley de instrucción obligatoria que imponía multas a los padres remisos por 25 pesos o cárcel si no llevaban a sus hijos a la escuela. Al mismo tiempo apuntaba hacia la uniformidad educativa fijando horarios y materias para las escuelas públicas. Para echar a andar el nuevo reglamento, el Ayuntamiento tuvo que abrir 24 nuevas escuelas y, por tanto, contratar a más profesoras y ayudantes. A partir de $1892 \mathrm{el}$ monto asignado a sueldos se elevó hasta $59 \%$ del gasto.

Hacia finales de 1893, una queja de las directoras se presentó a la Comisión de Instrucción Pública. En ella pedían la nivelación de sus sueldos con los de los directores, solicitud que nunca les sería concedida, pero que quizá tuviera que ver con el creciente peso que este género debió tener al interior de la estructura docente hacia la década de los noventa:

[...] sin pretender rebajar en manera alguna el trabajo y mérito de los señores profesores del municipio, hacemos notar que estos señores disfrutan del sueldo de sesenta pesos mensuales pudiendo dedicarse a otros trabajos fuera de su casa después de terminadas las horas de la escuela; y nosotras que tenemos a nuestro cargo más de las mismas ramas de enseñanza que aquéllos una labor más: la costura que nos obliga a permanecer mayor tiempo en nuestras escuelas, y que, en razón de nuestro sexo, no podemos aceptar fuera de nuestro domicilio ninguna otra ocupación, apenas go- zamos del pequeño honorario de 45 pesos mensuales, notable desproporción. ${ }^{51}$

La extensión de la autoridad del ejecutivo sobre el Ayuntamiento culminó en 1896 cuando un decreto, fechado el 19 de mayo, dispuso que la instrucción primaria municipal pasara a depender exclusivamente del gobierno federal. Un mes después, la supresión de las alcabalas a nivel nacional confirmaba la medida y dejaba sin fondos al municipio para sostener sus escuelas. En 1.896, la Comisión de Instrucción Pública entregó al ejecutivo federal 113 planteles educativos: 50 escuelas para niños y 48 para niñas, seis escuelas foráneas mixtas, ocho nocturnas para hombres y una para mujeres. Ese sistema escolar contaba con una planta magisterial compuesta por 42 directores y 64 directoras, 128 ayudantes de las cuales 85 eran señoritas y 43 señores; 32 auxiliares, 27 femeninos y seis masculinos; diez profesores de dibujo, nueve de inglés, nueve conserjes y un inspector. ${ }^{52}$

Más de la mitad de los cargos docentes fueron ocupados por mujeres, pero es importante reiterar que los sueldos de las profesoras perdieron valor desde los años ochenta, pues antes de esa década las percepciones eran las mismas para ambos sexos. El crecimiento de la planta magisterial, a lo largo de 29 años, se dio a través de los ayudantes que eventualmente ocuparon puestos interinos como directores o directoras y pudieron, a través de una larga espera, acceder a la

${ }^{51}$ AHADF, Instrucción pública en general, vol. 2508 , exp. 2808 (1893).

s2 Ibid., vol. 2512, exp. 3128 (1896). 
propiedad de la plaza. En el cuadro 1 se presenta la estructura magisterial en diferentes años y nos da idea de ese sistema jerárquico: mientras la expansión en el número de los profesores presenta una trayectoria hacia el aumento de la base, los puestos directivos reflejan una estabilidad moderada (véase cuadro 1).

De la planta de profesores del Ayuntamiento en 1895, por lo menos 44 de ellos se hicieron acreedores a un reconocimiento por su antigüedad. Para aquellos que completaron más de 20 años de servicio, la Comisión les hizo entrega de una medalla de plata, y una de bronce para los que laboraron más de diez años. Este hecho revela la estabilidad en el empleo para casi la mitad de los directores, de entre los cuales la mayoría eran mujeres (véase cuadro 2 ).

\section{CONCLUSIONES}

A lo largo de este artículo he tratado de mostrar cómo el Ayuntamiento de la ciudad de México promovió la actuación de los profesores municipales a manera de una comunidad que se distinguía por ejercer una práctica común: la de educar. Como corporación tuvo en sus manos la disposición sobre los beneficios económicos y reguló el acceso a ellos, así como la entrada a la comunidad magisterial, de manera tal que, sin perjuicio de la competencia de otros maestros que buscaban las ventajas económicas que ofrecía el municipio, se asegurara la continuidad en la acción docente.

La tendencia expansiva de la educación municipal, derivada del crecimiento poblacional de la ciudad, llevó a la ampliación de la comunidad magisterial a través de una estructura jerárquica y, por tanto, a la pérdida de algunos beneficios, principalmente para las maestras. Hacia el interior del grupo de profesores municipales, la Comisión de Instrucción Pública propició y avaló la existencia de jerarquías y categorías basadas en el género, el mérito y la antigüedad, lo que permitió racionalizar los beneficios y las expectativas de los docentes. Los mejores salarios, las mejores casas y los puestos más importantes permanecieron abiertos principalmente para los directores, hasta el punto en que éstos pudieron competir entre sí para obtenerlos. El mérito obtenido a través del reconocimiento público y el arraigo en el vecindario serían piezas clave en ese cometido.

Al pasar las escuelas municipales al ejecutivo federal, los profesores perdieron la exclusividad que suponía estar bajo la protección del Ayuntamiento. Este espacio de actuación recíproca en el cual el municipio monopolizaba los beneficios y los profesores buscaban cerrar filas para evitar la competencia, no es abordado para esta época por las investigaciones históricas. Analizando la situación de los maestros municipales de la ciudad de México, nos encontramos con que el poder adquisitivo de más de la mitad de ellos era mucho mayor que su salario por el simple hecho de que no pagaban renta de la casa que habitaban, pues era el mismo inmueble donde se ubicaba la escuela, además, contaban con otros beneficios, como licencia por enfermedad y jubilación. Los profesores municipales de la ciudad participaron en común para proteger sus intereses. El Ayuntamiento cubrió sus beneficios y reflejó en su práctica las demandas de exclusividad de la docencia municipal, con ello también aseguraría una red clientelar y un espacio de cierta autonomía para su gestión. 
Cuadro 1. Estructura interna del profesorado municipal para diferentes años

\begin{tabular}{|c|c|c|c|c|c|c|}
\hline$A \tilde{n} o$ & Directores & Directoras & $\begin{array}{l}\text { Directoras } \\
\text { elementales }\end{array}$ & $\begin{array}{l}\text { Directoras } \\
\text { de párvulos }\end{array}$ & Ayudantes & Total \\
\hline 1868 & 12 & 12 & & & & 24 \\
\hline 1875 & 24 & 29 & & & & 53 \\
\hline 1884 & 19 & 29 & 30 & & 27 & 105 \\
\hline 1888 & 34 & 47 & & 4 & 45 & 130 \\
\hline 1892 & 48 & 63 & & & 109 & 220 \\
\hline 1895 & 49 & 64 & & & 122 & 235 \\
\hline
\end{tabular}

Fuente: Propia elaborada con los datos de AHDF, Memoria del Ayuntamiento para esos años.

Cuadro 2. Antigüedad de los profesores para 1895

$\begin{array}{ccccc}\begin{array}{c}\text { Número de } \\ \text { profesores }\end{array} & \begin{array}{c}\text { Número de } \\ \text { profesoras }\end{array} & \text { Años de servicio } & \text { Fecha de inicio } & \begin{array}{c}\text { Total de } \\ \text { profesores }\end{array} \\ 1 & & 27 & 1868 & 1 \\ 1 & 1 & 26 & 1870 & 1 \\ & 1 & 24 & 1871 & 2 \\ & 3 & 22 & 1873 & 3 \\ 1 & 1 & 21 & 1874 & 1 \\ 2 & 2 & 20 & 1875 & 2 \\ 1 & 1 & 19 & 1876 & 2 \\ 2 & 2 & 18 & 1877 & 4 \\ & 3 & 17 & 1878 & 4 \\ & 1 & 16 & 1879 & 3 \\ 2 & 6 & 15 & 1880 & 6 \\ 2 & 1 & 14 & 1881 & 4 \\ & 4 & 13 & 1882 & 2 \\ & 4 & 12 & 1883 & 6\end{array}$

Fuente: Propia elaborada con datos de AHDF, Instrucción pública en general, vol. 2519, exp. 3037 (1895). 


\section{ARCHIVO}

AHDF Archivo Histórico del Distrito Federal

\section{BIBLIOGRAFÍA}

-Arnaut, Alberto, Historia de una profesión. Los maestros de educación primaria en México, 1887 1994, Centro de Investigación y Docencia Económica, México, 1996.

-Bazant, Mílada, Historia de la educación duranté el porfiriato, El Colegio de México, México, 1995.

-Chaoul, Ma. Eugenia, "La instrucción pública y el Ayuntamiento de la ciudad de México: una visión de la educación municipal en la ciudad (1867-1896)", tesis de maestría, Instituto de Investigaciones Dr. José María Luis Mora, México, 1998.

-Dublán, Manuel y José María Lozano, Colección legislativa completa de la república mexicana, con todas las disposiciones expedidas para la federación, el Distrito y los territorios federales, Tipografía de la viuda de Francisco Díaz de León, México, 1908, vols. 6, 9 y 10.

-Galván, Luz Elena, Soledad compartida. Una bistoria de maestros: 1908-1910, CIESAS, México, 1991.

-Gortari Rabiela, Hira de y Regina Hernández Franyuti (comps.), La ciudad de México y el Distrito Federal. Una bistoria compartida, Instituto Mora/Departamento del Distrito Federal, México, 1988.

-Liceaga, Eduardo, Mis recuerdos de otros tiempos, Talleres Gráficos de la Nación, México, 1949.
-Lira, Andrés, Comunidades indigenas frente a la ciudad de México. Tenochtitlan y Tlatelolco, sus pueblos y sus barrios, 1812-1919, El Colegio de México/El Colegio de Michoacán, México, 1983.

-Morales Meneses, Ernesto, Tendencias educativas oficiales en México, 1821-1911, Editorial Porrúa, México, 1983.

-Rodríguez Kuri, Ariel, La experiencia olvidada. El Ayuntamiento de México: política y gobierno, 1876-1912, El Colegio de México/UAMAzcapotzalco, México, 1996.

-Staples, Anne, Educar: panacea del México independiente, Secretaría de Educación Pública/El Caballito, México, 1985.

-Tanck de Estrada, Dorothy, La educación ilustrada (1786-1836). Educación primaria en la ciudad de México, El Colegio de México, México, 1977.

- "Las Cortes de Cádiz y el desarrollo de la educación en México", Historia Mexicana, núm. 29, 1979, pp. 3-34.

_, "Ilustración y liberalismo en el programa de educación primaria de Valentín Gómez Farías", Historia Mexicana, núm. 33, 1984, pp. 463-508.

- "Tensión en la torre de marfil. La educación en la segunda mitad del siglo XVIII mexicano" en Josefina Vázquez et al., Ensayos sobre la bistoria de la educación en México, El Colegio de México, México, 1981.

-Weber, Max, Economía y Sociedad, Fondo de Cultura Económica, México, 1977, t. I. 